\title{
A Pharmacokinetic Bridging Study to Compare Systemic Exposure to Budesonide between Budesonide Oral Suspension and ENTOCORT EC in Healthy Individuals
}

\author{
Ivy H. Song ${ }^{1}\left(\mathbb{D} \cdot\right.$ Richard D. Finkelman $^{1} \cdot$ Lan Lan $^{1}$
}

Accepted: 22 September 2020 / Published online: 15 October 2020

(c) The Author(s) 2020

\begin{abstract}
Background and Objectives Currently, there are no US FDA-approved therapies for eosinophilic esophagitis (EoE). Budesonide oral suspension (BOS; SHP621, TAK-721) is a viscous, muco-adherent, oral formulation of budesonide that is in phase III development for the treatment of EoE. BOS $2 \mathrm{mg}$ twice daily was studied in 12- and 36-week phase III studies for the induction and maintenance of clinical remission in adults and adolescents with EoE (NCT02605837 and NCT02736409). ENTOCORT EC is a gelatin capsule formulation of budesonide that is FDA-approved for the treatment of mild-to-moderate active Crohn's disease (CD) in adults and children. This study compared the systemic exposure to budesonide from BOS with that from ENTOCORT EC, aiming to provide the pharmacokinetic (PK) bridge to the safety data of ENTOCORT EC. Methods Healthy adult volunteers $(n=22)$ were enrolled in an open-label, single-center, crossover study. Participants received a single oral dose of BOS $2 \mathrm{mg}$ and a single oral dose of ENTOCORT EC $9 \mathrm{mg}$ under fasting conditions in a randomized sequence, with a 48-h washout period between treatments. PK parameters were calculated by non-compartmental analysis and compared between treatments using a mixed-effects model with sequence and treatment as fixed effects and individuals within sequence as a random effect.

Results Plasma budesonide concentrations showed that budesonide was absorbed significantly faster from BOS $2 \mathrm{mg}$ than from ENTOCORT EC $9 \mathrm{mg}$, with peak concentrations reached at 1.5 and $4 \mathrm{~h}$, respectively $(p<0.001)$. Systemic exposure to budesonide after a single oral dose of BOS $2 \mathrm{mg}$ was lower than that observed after a single oral dose of ENTOCORT EC $9 \mathrm{mg}$; the least squares geometric mean maximum plasma concentration and the area under the concentration-time curve from the time of dosing to infinity and from the time of dosing to the last measurable concentration of budesonide after BOS $2 \mathrm{mg}$ were $71.1 \%, 33.5 \%$, and 33.6\% of those after ENTOCORT EC $9 \mathrm{mg}$, respectively. No notable differences in treatment-emergent adverse events were observed between individuals treated with either drug; all events were mild and none resulted in discontinuation from the study.

Conclusions This study demonstrated that systemic exposure to budesonide after a single oral dose of BOS $2 \mathrm{mg}$ was lower than that after a single oral dose of ENTOCORT EC $9 \mathrm{mg}$. These results provide PK bridging data to compare BOS with therapeutic doses of ENTOCORT EC with respect to safety information.
\end{abstract}

Ivy H. Song

ivy.song@takeda.com

Richard D. Finkelman

richard.finkelman@takeda.com

Lan Lan

lan.lan@takeda.com

1 Shire Human Genetic Therapies, Inc., a Member of the Takeda Group of Companies, 300 Shire Way, Lexington, MA 02421, USA 


\section{Key Summary Points}

A pharmacokinetic (PK) bridging study was conducted to compare the systemic exposure to budesonide from budesonide oral suspension (BOS), an oral formulation of budesonide that is in phase III development for the treatment of eosinophilic esophagitis, with that from ENTOCORT EC, a capsule formulation of budesonide indicated for the treatment of Crohn's disease (CD)

Systemic exposure to budesonide from BOS $2 \mathrm{mg}$ twice daily (phase III study dose) was estimated to be lower than that from ENTOCORT EC 9 mg once daily (approved CD induction dose) and similar to that from ENTOCORT EC $6 \mathrm{mg}$ once daily (approved CD maintenance dose)

These results provide PK bridging data to compare BOS $2 \mathrm{mg}$ twice daily with therapeutic doses of ENTOCORT EC with respect to safety information

\section{Introduction}

Eosinophilic esophagitis (EoE) is a chronic, immunemediated disease characterized by chronic symptoms of esophageal dysfunction and eosinophilic inflammation [1]. Symptoms in adults include dysphagia, esophageal stricture, and food impaction [2]. These symptoms disrupt and restrict daily activities, affecting the health-related quality of life of patients and their families [3-5]. The estimated prevalence and incidence of EoE in the USA is approximately 0.5-1 per 1000 people and 1 in 10,000 new diagnoses each year, respectively [6].

There are currently no US FDA-approved therapies for EoE. Clinical guidelines recommend proton pump inhibitors, dietary therapies, swallowed topical corticosteroids (STCs), and esophageal dilation [7, 8]. Consistent and effective delivery is key to the efficacy of STCs [9]; consequently, their off-label use in the treatment of EoE can be problematic. Administration of STCs using metered-dose inhalers can result in suboptimal drug delivery, and budesonide slurries mixed by patients produce variable drug concentrations and mucosal contact times, which may limit their effectiveness in treating EoE symptoms [10]. Given the clinical outcomes associated with EoE and the absence of approved treatments indicated for the disease, there is an unmet need for novel therapies.

Budesonide oral suspension (BOS) is a muco-adherent formulation of budesonide with standardized viscosity and concentration, designed to increase the residence time of the drug on the esophageal surface [11]. BOS is in development for the treatment of EoE in adults and adolescents as a swallowed suspension. In a phase II clinical trial (ClinicalTrials.gov identifier: NCT01642212), BOS 2 mg twice daily significantly improved dysphagia symptoms, histological response, and eosinophil counts in adolescents and adults (11-40 years of age) with EoE [11]. Given the unmet medical need for an approved treatment for EoE, BOS was granted breakthrough designation by the FDA in 2016. Phase III trials in patients with EoE who were 11-55 years of age were initiated and have since been completed (ClinicalTrials. gov identifiers: NCT02605837 and NCT02736409).

Following oral administration and absorption, budesonide undergoes high (80-90\%) first-pass hepatic metabolism via cytochrome P450 (CYP) 3A4 and has a high plasma clearance of approximately $0.9-1.8 \mathrm{~L} / \mathrm{min}$ in healthy individuals [12-14]. Budesonide is also a substrate of P-glycoprotein, which is highly expressed in the colon and small intestine [15-17]. Consequently, orally administered budesonide has high topical glucocorticoid activity with minimal systemic exposure $[13,18]$. The systemic effects mediated by corticosteroids are minimized for budesonide, which may be attributed to its relatively low bioavailability [18]. The major metabolites of budesonide, $6 \beta$-hydroxy budesonide, and 16 $\alpha$-hydroxy prednisolone have negligible glucocorticoid activity $(<1 \%)$ and are predominantly excreted renally [14]. Several budesonide products are approved for different indications in the USA and other countries, including RHINOCORT (McNeil Products Ltd, Berkshire, UK), a nasal spray indicated for the treatment of seasonal allergic rhinitis (64 mg once daily), and ENTOCORT EC (AstraZeneca, Södertälje, Sweden), an oral formulation indicated for the induction (9 mg once daily) and maintenance (6 mg once daily) treatment of mild-to-moderate active Crohn's disease (CD) $[14,19]$. Thus, the safety of budesonide has been evaluated extensively. This analysis compared systemic exposure to budesonide from the BOS formulation used in phase III trials with that from ENTOCORT EC, and aimed to provide a pharmacokinetic (PK) bridge to the safety data of ENTOCORT EC.

\section{Methods}

\subsection{Study Design and Population}

This phase I crossover study aimed to compare the PK of budesonide from a single oral dose of BOS $2 \mathrm{mg}(0.2 \mathrm{mg} /$ $\mathrm{mL}$ in a volume of $10 \mathrm{~mL}$ ) with a single oral dose of ENTOCORT EC $9 \mathrm{mg}$ (three $3 \mathrm{mg}$ gelatin capsules) in healthy individuals. 
BOS $2 \mathrm{mg}$ twice daily is the dose used in ongoing phase III studies in patients with EoE; therefore, BOS $2 \mathrm{mg}$ was selected for this single-dose, blinded study [20, 21]. In adults, the recommended dose of ENTOCORT EC is $9 \mathrm{mg}$ once daily and $6 \mathrm{mg}$ once daily for the treatment and maintenance of clinical remission of mild-to-moderate active CD, respectively [14]. ENTOCORT EC $9 \mathrm{mg}$ once daily was selected as the comparative clinical dose because the PK of budesonide from this formulation are dose proportional following repeated oral administration of 3-15 $\mathrm{mg}$ [14].

Healthy adults who were $18-50$ years of age, inclusive, with a body mass index (BMI) of $18-30 \mathrm{~kg} / \mathrm{m}^{2}$, inclusive, a body weight $\geq 50 \mathrm{~kg}$, and hemoglobin levels $\geq 12 \mathrm{~g} / \mathrm{dL}$ were included in this randomized, open-label, single-center, crossover study. Individuals with a current or recent (within the past year) history of any gastrointestinal (GI) disorder, such as esophagitis, gastroesophageal reflux disease or gastritis, or of any medical condition requiring corticosteroid treatment, or who might have required corticosteroid treatment during the study (e.g. eczema, asthma or allergic rhinitis) were excluded from the study. Those who had used any medication (including over-the-counter, herbal or homeopathic preparations), with the exception of hormone replacement therapy or hormonal contraceptives and occasional use of ibuprofen or acetaminophen, within the 14 days prior to the first dose of either study drug were also excluded, as were individuals who had ingested known CYP3A4 inhibitors within the 7 days prior to the first dose of study treatment. Any individuals who had received BOS $2 \mathrm{mg}$, ENTOCORT EC $9 \mathrm{mg}$, or any other corticosteroid within 30 days of the first dose of study medication were also excluded.

Participants were randomly assigned to one of two treatment sequences. In treatment sequence 1, participants received a single oral dose of BOS $2 \mathrm{mg}$, followed by a single oral dose of ENTOCORT EC $9 \mathrm{mg}$ with a 48-h washout period between each treatment. Participants in treatment sequence 2 received ENTOCORT EC $9 \mathrm{mg}$ first, followed by BOS $2 \mathrm{mg}$, with a 48-h washout period between each treatment (Fig. 1). Participants were required to fast for approximately $10 \mathrm{~h}$ before dose administration and to continue fasting through to $4 \mathrm{~h}$ after administration of each study drug. In addition, water intake was restricted (except for water to administer ENTOCORT EC), starting $4 \mathrm{~h}$ before and continuing up to $2 \mathrm{~h}$ after administration of each drug. After study treatment, patients received a follow-up telephone call, during which any serious adverse events (SAEs), adverse events (AEs), and use of concomitant medications were recorded.

The study was conducted in accordance with the ethical principles of the Declaration of Helsinki, the International Conference on Harmonisation Good Clinical Practice guidelines, and applicable regulatory requirements. Approval from an Institutional Review Board was obtained, and informed consent was obtained from all individual participants included in the study.

\subsection{PK Assessments}

Serial blood draws for PK assessments were performed up to $24 \mathrm{~h}$ after dosing: every $15 \mathrm{~min}$ up to $1 \mathrm{~h}$ postdose; at $1.5 \mathrm{~h}$ postdose; every $2 \mathrm{~h}$ up to $16 \mathrm{~h}$ postdose; and at $24 \mathrm{~h}$ postdose. Blood samples were immediately chilled and centrifuged $\left(\right.$ at $4{ }^{\circ} \mathrm{C}$ ) at $1500 \mathrm{~g}$ for $15 \mathrm{~min}$. The separated plasma samples were stored at $-70{ }^{\circ} \mathrm{C}$ and shipped to the bioanalytical laboratory for analysis. Plasma concentrations of budesonide were determined using a validated bioanalytical method [22]. Budesonide was obtained from Sigma-Aldrich (St Louis, MO, USA) and was subsequently used to prepare standard and quality control solutions, which were determined based on the nominal concentrations of budesonide.

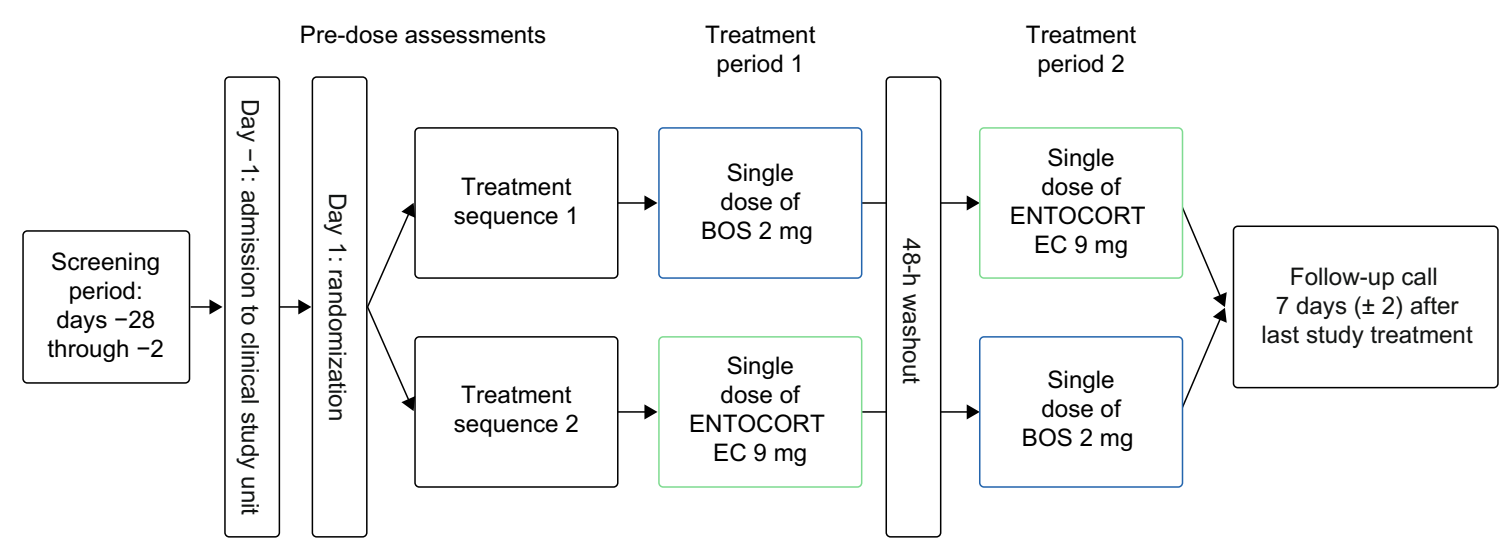

Fig. 1 Phase I crossover study design. Participants were randomly assigned to one of two treatment sequences, with a 48-h washout period between each treatment: BOS $2 \mathrm{mg}(0.2 \mathrm{mg} / \mathrm{mL}$ in a volume of $10 \mathrm{~mL}$ ) or ENTOCORT EC $9 \mathrm{mg}$ (three 3-mg gelatin capsules) after a 10-h fasting period. Serial blood samples for determining plasma budesonide concentrations were collected in both treatment periods at predose and through $24 \mathrm{~h}$ postdose. BOS budesonide oral suspension 


\subsection{PK Data Analysis}

Analyses of PK data were performed for all participants who had taken at least one dose of BOS $2 \mathrm{mg}$ or ENTOCORT EC $9 \mathrm{mg}$ and who had at least one measurable postdose plasma concentration of budesonide that was reportable for either treatment. PK parameters were calculated from the plasma concentration-time data using non-compartmental methods, and all calculations were based on actual sampling times. PK parameters measured were area under the concentration-time curve from the time of dosing to infinity $\left(\mathrm{AUC}_{\infty}\right)$; area under the concentration-time curve from the time of dosing to the last measurable concentration $\left(\mathrm{AUC}_{\mathrm{t}}\right)$; maximum observed plasma concentration $\left(C_{\max }\right)$; apparent clearance $(\mathrm{CL} / F)$; terminal half-life $\left(t_{1 / 2}\right)$; time to first quantifiable plasma concentration after $\operatorname{dosing}\left(t_{\mathrm{lag}}\right)$; time of $C_{\max }$ $\left(t_{\max }\right)$; and apparent volume of distribution associated with the terminal slope $\left(V_{z} / F\right)$.

\subsection{Safety Assessments}

Safety was evaluated by daily recording of AEs throughout the study period and by the assessment of vital signs (every day), clinical laboratory parameters (day -1 and final day of treatment), and 12-lead electrocardiograms (ECGs; days $1,2,4$, and 5). An AE was defined as any untoward medical event that occurred after the individual provided informed consent to participate in the study, irrespective of whether or not it was associated with BOS $2 \mathrm{mg}$ or ENTOCORT EC $9 \mathrm{mg}$, and irrespective of whether or not it was deemed by the investigator to be treatment-related. Treatment-emergent AEs (TEAEs) were defined as any AE that started, deteriorated in severity, or increased in severity on or after the date of the first dose of study drug through to 3 days after the last dose administered in each of the respective study periods.

\subsection{Statistical Analyses}

Log-transformed PK parameters $\left(\mathrm{AUC}_{\infty}, \mathrm{AUC}_{\mathrm{t}}\right.$, and $\left.C_{\max }\right)$ were compared between treatments using a mixed-effect model for a crossover design with fixed factors for sequence and treatment, and a random factor for individuals within sequence. Point estimates and associated $90 \%$ confidence intervals (CIs) were constructed for the differences in logtransformed PK parameters. These values were back-transformed to provide point estimates for the ratio of geometric least squares means and associated $90 \%$ CIs on the original scale. The geometric mean $t_{\max }$ of budesonide was compared with BOS $2 \mathrm{mg}$ and ENTOCORT EC $9 \mathrm{mg}$ treatments using the Wilcoxon signed-rank test.

\section{Results}

\subsection{Baseline Demographics and Clinical Characteristics}

In total, 22 individuals with a mean (standard deviation [SD]) age of 39.2 years (10.2) and a mean (SD) BMI of $27.8 \mathrm{~kg} / \mathrm{m}^{2}$ (2.3) were enrolled in this study; $50 \%$ were women. Eleven participants were assigned to treatment sequence 1 and 11 were assigned to treatment sequence 2 ; all participants completed the study (Table 1). Baseline demographics were generally similar between the two treatment sequence groups, with some differences noted for ethnicity (Table 1). In treatment sequence group 1, six participants (54.5\%) were Hispanic or Latino and five participants $(45.5 \%)$ were non-Hispanic or non-Latino. In treatment sequence group 2, nine participants (81.8\%) were Hispanic or Latino and two participants (18.2\%) were non-Hispanic or non-Latino.
Table 1 Baseline demographics and characteristics

\begin{tabular}{llll}
\hline Demographic/characteristic & Treatment sequence 1 & Treatment sequence 2 & Overall \\
\hline$N$ & 11 & 11 & 22 \\
Age, years & $37.5(11.5)$ & $40.9(9.0)$ & $39.2(10.2)$ \\
Men [n (\%)] & $4(36.4)$ & $7(63.6)$ & $11(50.0)$ \\
Race [n (\%)] & & & \\
$\quad$ White & $10(90.9)$ & $9(81.8)$ & $19(86.4)$ \\
Black & $1(9.1)$ & $2(18.2)$ & $3(13.6)$ \\
Ethnicity [n (\%)] & & & $15(68.2)$ \\
Hispanic or Latino & $6(54.5)$ & $9(81.8)$ & $7(31.8)$ \\
$\quad$ Non-Hispanic or non-Latino & $5(45.5)$ & $2(18.2)$ & $78.2(11.3)$ \\
Weight, kg & $75.6(10.1)$ & $80.8(12.4)$ & $167.4(10.0)$ \\
Height, cm & $164.2(9.5)$ & $170.5(9.8)$ & $27.8(2.3)$ \\
BMI, kg/m ${ }^{2}$ & $28.0(2.0)$ & $27.7(2.7)$ & \\
\hline
\end{tabular}

$B M I$ body mass index, $S D$ standard deviation

Data are expressed as mean (SD) unless otherwise stated 


\subsection{PK Results}

PK parameters $\left(\mathrm{AUC}_{\infty}, t_{1 / 2}, \mathrm{CL} / F\right.$ and $\left.V_{\mathrm{z}} / F\right)$ could not be reliably calculated for one individual who received ENTOCORT EC $9 \mathrm{mg}$. Following oral administration of BOS $2 \mathrm{mg}$, mean plasma concentrations of budesonide increased steadily and peaked approximately $1.5 \mathrm{~h}$ after dosing (Fig. 2). In contrast, ENTOCORT EC $9 \mathrm{mg}$ showed significantly slower absorption than BOS $2 \mathrm{mg}$, with the peak plasma concentration at approximately $4 \mathrm{~h}(p<0.001)$ [Table 2]. Systemic exposure to budesonide after a single oral dose of BOS $2 \mathrm{mg}$ was lower than after a single dose of ENTOCORT EC $9 \mathrm{mg}$; the geometric least squares mean $\mathrm{AUC}_{\mathrm{t}}, \mathrm{AUC}_{\infty}$, and $C_{\max }$ values for BOS $2 \mathrm{mg}$ were $33.6 \%, 33.5 \%$, and $71.1 \%$, respectively, of those observed for ENTOCORT EC $9 \mathrm{mg}$ (Table 2).

\subsection{Safety Results}

In total, six participants (27.3\%) experienced TEAEs. Four individuals (18.2\%) treated with BOS $2 \mathrm{mg}$ reported four TEAEs, and two individuals (9.1\%) treated with ENTOCORT EC $9 \mathrm{mg}$ reported two TEAEs. All TEAEs were reported as mild in severity. No TEAEs resulted in treatment discontinuation (Table 3). There were no notable differences in TEAEs between the two treatments. No clinically relevant changes in vital signs, clinical laboratory parameters, or ECG parameters were observed after treatment with BOS or ENTOCORT EC.

\section{Discussion}

This study provides PK bridging data to compare the safety of BOS with that of ENTOCORT EC. The rate of absorption of budesonide from BOS $2 \mathrm{mg}$ was faster than that from ENTOCORT EC $9 \mathrm{mg}$, with the mean peak plasma concentration occurring $2.5 \mathrm{~h}$ earlier. This observation is consistent with the differences in the formulations and anticipated locations of action of each drug. Although both drugs are administered orally, ENTOCORT EC is formulated for release in
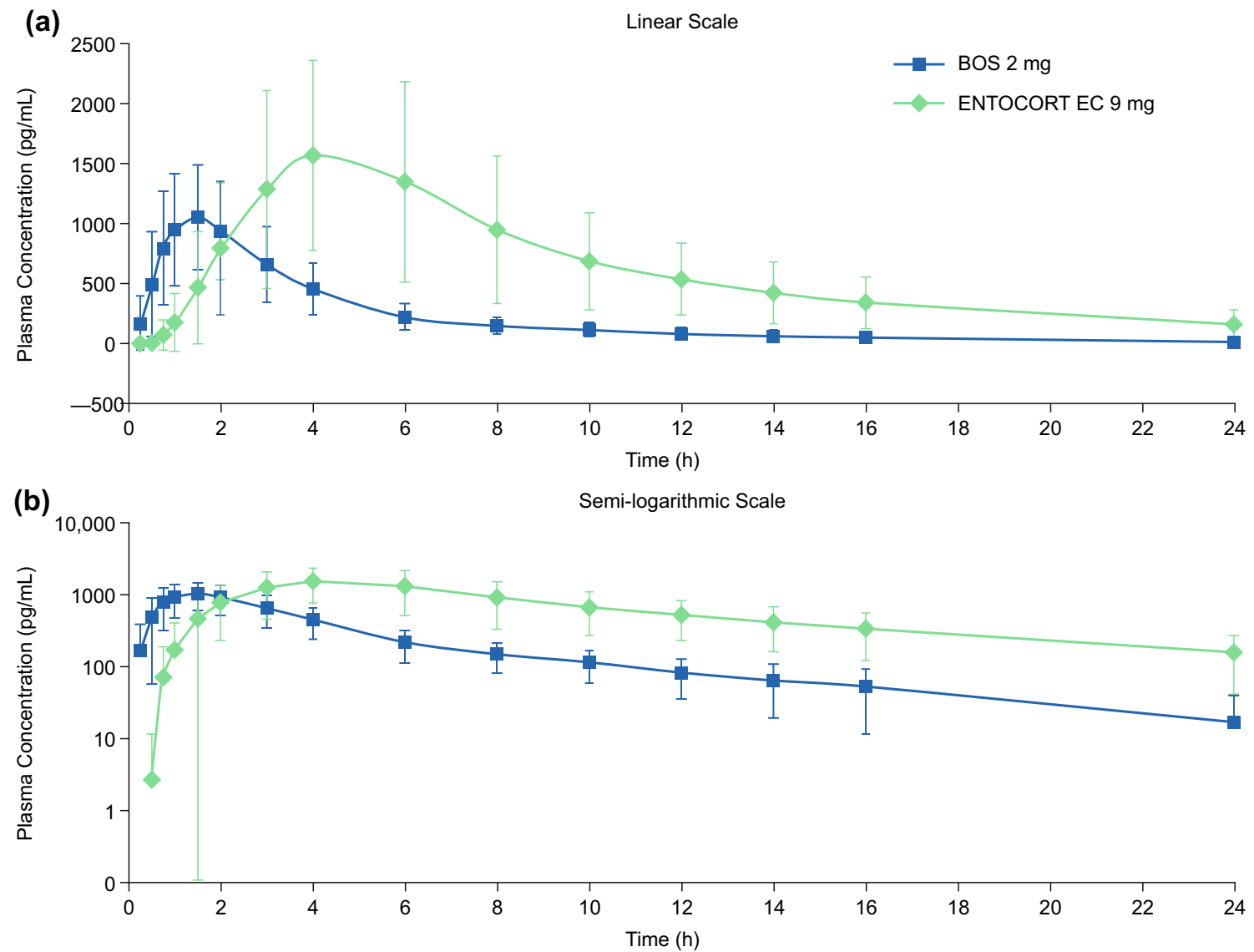

Fig. 2 Mean \pm SD plasma concentrations of budesonide over time after a single dose of BOS $2 \mathrm{mg}$ or ENTOCORT EC $9 \mathrm{mg}$ on linear and semi-logarithmic scales. Plasma concentrations of budesonide peaked at approximately $1.5 \mathrm{~h}$ for BOS $2 \mathrm{mg}$ and showed signifi- cantly faster absorption than ENTOCORT EC $9 \mathrm{mg}$, which peaked at approximately $4 \mathrm{~h}$ after dosing. BOS budesonide oral suspension, $S D$ standard deviation 
Table 2 Summary of budesonide pharmacokinetic parameters

\begin{tabular}{|c|c|c|}
\hline \multirow[t]{2}{*}{ PK parameter } & \multicolumn{2}{|l|}{ Treatment } \\
\hline & BOS $2 \mathrm{mg}[n=22]$ & ENTOCORT EC $9 \mathrm{mg}[n=22]$ \\
\hline \multicolumn{3}{|l|}{$\mathrm{AUC}_{\infty}, \mathrm{h} \times \mathrm{ng} / \mathrm{mL}$} \\
\hline$n$ & 22 & 21 \\
\hline Geometric mean $(95 \% \mathrm{CI})$ & $4.524(3.612-5.666)$ & $13.745^{\mathrm{a}}(10.446-18.085)$ \\
\hline $\begin{array}{l}\text { Ratio of geometric LS means ( } 90 \% \mathrm{CI}) \\
\text { relative to ENTOCORT EC } 9 \mathrm{mg}\end{array}$ & $0.335(0.302-0.373)^{\mathrm{a}}$ & $0.335(0.302-0.373)^{\mathrm{a}}$ \\
\hline \multicolumn{3}{|l|}{$\mathrm{AUC}_{\mathrm{t}}, \mathrm{h} \times \mathrm{ng} / \mathrm{mL}$} \\
\hline$n$ & 22 & 22 \\
\hline Geometric mean $(95 \% \mathrm{CI})$ & $4.257(3.394-5.339)$ & $12.682(9.807-16.402)$ \\
\hline $\begin{array}{l}\text { Ratio of geometric LS means }(90 \% \mathrm{CI}) \\
\text { relative to ENTOCORT EC } 9 \mathrm{mg}\end{array}$ & $0.336(0.301,0.374)$ & $0.336(0.301,0.374)$ \\
\hline \multicolumn{3}{|l|}{$C_{\max }, \mathrm{ng} / \mathrm{mL}$} \\
\hline Geometric mean $(95 \% \mathrm{CI})$ & $1.063(0.863-1.310)$ & $1.496(1.165-1.921)$ \\
\hline $\begin{array}{l}\text { Ratio of geometric LS means }(90 \% \mathrm{CI}) \\
\text { relative to ENTOCORT EC } 9 \mathrm{mg}\end{array}$ & $0.711(0.638-0.792)$ & $0.711(0.638-0.792)$ \\
\hline \multicolumn{3}{|l|}{$t_{1 / 2}, \mathrm{~h}$} \\
\hline Geometric mean $(95 \% \mathrm{CI})$ & $5.05(4.40-5.79)$ & $6.02^{\mathrm{a}}(5.55-6.53)$ \\
\hline \multicolumn{3}{|l|}{$\mathrm{CL} / F, \mathrm{~L} / \mathrm{h}$} \\
\hline Geometric mean $(95 \% \mathrm{CI})$ & $442.1(353.0-553.6)$ & $654.8^{\mathrm{a}}(497.6-861.6)$ \\
\hline \multicolumn{3}{|l|}{$V_{\mathrm{z}} / F, \mathrm{~L}$} \\
\hline Geometric mean $(95 \% \mathrm{CI})$ & $3218.5(2804.3-3693.9)$ & $5688.1^{\mathrm{a}}(4496.0-7196.2)$ \\
\hline \multicolumn{3}{|l|}{$t_{\max }, \mathrm{h}$} \\
\hline Median (min, max) & $1.5(0.5,2.0)$ & $4.0(2.0,6.0)$ \\
\hline \multicolumn{3}{|l|}{$t_{\mathrm{lag}}, \mathrm{h}$} \\
\hline Median (min, max) & $0(0,0.25)$ & $0.5(0.25,1.02)$ \\
\hline
\end{tabular}

$A U C_{\infty}$ area under the concentration-time curve from the time of dosing to infinity, $A U C_{t}$ area under the concentration-time curve from the time of dosing to the last measurable concentration, BOS budesonide oral suspension, $C I$ confidence interval, $C L / F$ apparent clearance, $C_{\max }$ maximum observed concentration, $L S$ least squares, $P K$ pharmacokinetic, $t_{1 / 2}$ terminal half-life, $t_{l a g}$ time to first quantifiable plasma concentration after dosing, $t_{\max }$ time to $C_{\max }, V_{z} / F$ apparent volume of distribution associated with the terminal slope ${ }^{a}$ For these calculations, the number of participants was 21 because PK parameters could not be calculated for one individual who received ENTOCORT EC $9 \mathrm{mg}$ the small intestine, whereas BOS is a viscous suspension, designed to increase the residence time of budesonide on the esophageal surface $[11,15]$.

Based on the geometric mean half-life of budesonide $(5.1 \mathrm{~h})$ observed in this study, there is no expected accumulation with once-daily dosing, and minimal $(<15 \%)$ expected accumulation of BOS with twice-daily dosing (used in phase III studies). Systemic exposure to budesonide from ENTOCORT EC $9 \mathrm{mg}$ in this study was similar to a previous investigation of $\mathrm{PK}$ in healthy adults in which the mean $C_{\max }$ and the steady state AUC for budesonide were $1.50 \pm 0.79 \mathrm{ng} /$ $\mathrm{mL}$ and $14.13 \pm 7.33 \mathrm{~h} \times \mathrm{ng} / \mathrm{mL}$, respectively, following oral administration of ENTOCORT EC $9 \mathrm{mg}$ once daily [14].

Systemic exposure to budesonide observed after a single dose of BOS $2 \mathrm{mg}$ was lower than that after a single dose of ENTOCORT EC $9 \mathrm{mg}$, as shown by the lower geometric mean $\mathrm{AUC}_{\infty}, \mathrm{AUC}_{t}$, and $C_{\text {max }}$. ENTOCORT EC $9 \mathrm{mg}$ once daily is approved for the treatment of mild-to-moderate active CD involving the ileum and/or the ascending colon, and ENTOCORT EC $6 \mathrm{mg}$ once daily is approved for the maintenance of clinical remission of mild-to-moderate $\mathrm{CD}$ [14]. The clinical dosing regimen for both the induction and maintenance of clinical remission of EoE studied in the phase III pivotal trial program for BOS is $2 \mathrm{mg}$ twice daily [20, 21]. Within therapeutic doses, budesonide exhibits linear PK properties; following repeated oral administration of 3-15 mg, the PK of budesonide from ENTOCORT EC is dose proportional [15]. Therefore, PK parameters for BOS $2 \mathrm{mg}$ twice daily and ENTOCORT EC $9 \mathrm{mg}$ once daily and $6 \mathrm{mg}$ once daily were estimated by superposition using the PK data from a single oral dose of BOS $2 \mathrm{mg}$ and a single oral dose of ENTOCORT EC $9 \mathrm{mg}$ determined in this study, under the assumption of linear and time-independent PK. When accounting for the different dosing frequencies of BOS and ENTOCORT EC, the daily AUC and the $C_{\max }$ of budesonide from BOS $2 \mathrm{mg}$ twice daily at steady state are 
Table 3 Treatment-emergent adverse events by system organ class and treatment at onset

\begin{tabular}{|c|c|c|c|c|}
\hline & \multicolumn{2}{|c|}{$\begin{array}{l}\text { BOS } 2 \mathrm{mg} \\
{[n=22]}\end{array}$} & \multicolumn{2}{|c|}{$\begin{array}{l}\text { ENTOCORT } \\
\text { EC } 9 \mathrm{mg} \\
{[n=22]}\end{array}$} \\
\hline & $n(\%)$ & $m$ & $n(\%)$ & $m$ \\
\hline \multicolumn{5}{|l|}{ TEAEs } \\
\hline All & $4(18.2)$ & 4 & $2(9.1)$ & 2 \\
\hline Serious & 0 & 0 & 0 & 0 \\
\hline Severe & 0 & 0 & 0 & 0 \\
\hline Related to study drug & $4(18.2)$ & 4 & $2(9.1)$ & 2 \\
\hline \multicolumn{5}{|l|}{ TEAEs by system organ class } \\
\hline Gastrointestinal disorders & $2(9.1)$ & 2 & $1(4.5)$ & 1 \\
\hline Dry mouth & $1(4.5)$ & 1 & $1(4.5)$ & 1 \\
\hline Flatulence & $1(4.5)$ & 1 & 0 & 0 \\
\hline Nervous system disorders & $2(9.1)$ & 2 & $1(4.5)$ & 1 \\
\hline Dizziness & 0 & 0 & $1(4.5)$ & 1 \\
\hline Headache & $2(9.1)$ & 2 & 0 & 0 \\
\hline
\end{tabular}

$B O S$ budesonide oral suspension, $n$ number of participants, $m$ number of events, TEAEs treatment-emergent adverse events

estimated to be approximately $67 \%$ and $71 \%$, respectively, of these parameters from ENTOCORT EC $9 \mathrm{mg}$ once daily, and similar to those from ENTOCORT EC $6 \mathrm{mg}$ once daily.

Although this study was not designed to evaluate the oral bioavailability of budesonide, the bioavailability for BOS $2 \mathrm{mg}$ is estimated to be $50.8 \%$ higher than that of ENTOCORT EC $9 \mathrm{mg}$, based on the dose-normalized AUC. As the oral bioavailability of budesonide from ENTOCORT EC $9 \mathrm{mg}$ is reported to be $9 \%$ in healthy adults in a fasted state [14], the oral bioavailability of budesonide from BOS $2 \mathrm{mg}$ is calculated to be $13.6 \%$ in healthy adults. Complete absorption of budesonide was observed following oral administration of ENTOCORT EC and other capsule formulations [12, 23]; therefore, complete absorption of budesonide following BOS administration is also expected. Given the differences in the formulations of BOS and ENTOCORT EC, budesonide is anticipated to be absorbed completely and mostly metabolized in the esophagus and upper GI tract following treatment with BOS, whereas budesonide from ENTOCORT EC is released and subsequently absorbed and metabolized in the lower GI tract. The higher oral bioavailability of budesonide from BOS compared with ENTOCORT EC observed in this study may be attributed to the lower first-pass metabolism of budesonide in the esophagus compared with the small intestine and colon as a consequence of the partition of esophageal drainage between the systemic (avoiding firstpass metabolism in the liver) and portal veins [24], the lower presence of CYP3A4 in the esophageal mucosa [25], and the higher presence of P-glycoprotein (of which budesonide is a substrate) in the small intestine [15-17].

\subsection{Study Limitations}

This study evaluated the PK of BOS in healthy individuals rather than patients with EoE; however, we expect the PK of BOS to be similar in these two populations based on findings from a population PK analysis that identified no significant differences in the PK of budesonide from BOS between healthy individuals and patients with EoE (internal data on file, 2019). In support, similar budesonide PK were reported in both healthy individuals and patients with $\mathrm{CD}$ who received ENTOCORT EC $9 \mathrm{mg}$ [26]. We also note that FDA guidelines recommend PK bridging studies in healthy individuals or patients to assess drug safety [27]. An additional limitation of this study is the difference in dosing frequencies between BOS ( $2 \mathrm{mg}$ twice daily) and ENTOCORT EC (9 mg once daily). Although PK data obtained after repeated doses may be the most relevant, we propose that an analysis of single-dose PK is appropriate because budesonide PK were shown to be linear and time-independent [14]. Although the ENTOCORT EC $6 \mathrm{mg}$ once-daily dose was not directly assessed in this study, systemic exposure to budesonide from ENTOCORT EC is linear between 3 and $15 \mathrm{mg}$. Therefore, budesonide PK from ENTOCORT EC $6 \mathrm{mg}$ once daily can be estimated via extrapolation of ENTOCORT EC $9 \mathrm{mg}$ once-daily PK data by direct dose adjustment. Thus, we propose that only including the ENTOCORT EC $9 \mathrm{mg}$ once-daily regimen in this study was appropriate and sufficient to compare ENTOCORT EC with BOS.

To address the limitations of this study, we provide a direct comparison of systemic exposure of budesonide between BOS $2 \mathrm{mg}$ twice daily observed in patients with EoE in the phase III study of BOS and ENTOCORT EC in patients with CD. In the phase III study of BOS, the systemic exposure to budesonide after BOS $2 \mathrm{mg}$ twice daily (mean daily AUC $10.1 \mathrm{~h} \times \mathrm{ng} / \mathrm{mL} ; C_{\max } 0.92 \mathrm{ng} / \mathrm{mL}$ ) in patients with EoE was lower than after ENTOCORT EC $9 \mathrm{mg}$ once daily (mean daily AUC $15.1 \mathrm{~h} \times \mathrm{ng} / \mathrm{mL} ; C_{\max } 1.7 \mathrm{ng} / \mathrm{mL}$ ) and similar to ENTOCORT EC $6 \mathrm{mg}$ once daily (mean daily AUC $10.1 \mathrm{~h} \times \mathrm{ng} / \mathrm{mL} ; C_{\max } 1.13 \mathrm{ng} / \mathrm{mL}$ ) in patients with $\mathrm{CD}$, based on dose proportional PK [14, 28].

\section{Conclusion}

This study demonstrated that systemic exposure to budesonide after a single oral dose of BOS $2 \mathrm{mg}$ was lower than that after a single oral dose of ENTOCORT EC $9 \mathrm{mg}$. Systemic exposure to budesonide from BOS $2 \mathrm{mg}$ twice daily was estimated to be lower than that from ENTOCORT EC $9 \mathrm{mg}$ once daily. Both drugs were well tolerated. These results provide PK bridging data to compare BOS $2 \mathrm{mg}$ twice daily with therapeutic doses of ENTOCORT EC with respect to safety information. 
Acknowledgments This study was funded by Shire ViroPharma Inc., a member of the Takeda group of companies. Writing support was provided by Madeleine Wynn of PharmaGenesis London, London, UK, and was funded by Shire Human Genetic Therapies Inc., a member of the Takeda group of companies. The authors would like to thank James Williams (an employee of Shire, a member of the Takeda group of companies) for his involvement in the scientific design of the study and editorial input into the manuscript.

\section{Declarations}

Funding This study was funded by Shire ViroPharma, Inc., a member of the Takeda group of companies.

Conflicts of Interest Ivy H. Song, Richard D. Finkelman, and Lan Lan are full-time employees of Shire, a member of the Takeda group of companies, and stockholders of Takeda.

Ethical Approval All procedures performed in studies involving human participants were in accordance with the ethical standards of the institutional and/or national research committee and with the 1964 Helsinki declaration and its later amendments or comparable ethical standards. This study was approved by the IntegReview Independent Review Board (dated 5 October 2017)

Consent to participate Consent to participate was obtained from all individuals included in this study.

Consent for publication Not applicable.

Availability of data and material Not applicable.

Code availability Not applicable.

Informed consent Informed consent was obtained from all individual participants included in this study.

Authors' contributions All authors contributed to the study design and analysis, and critically reviewed the manuscript.

Open Access This article is licensed under a Creative Commons Attribution-NonCommercial 4.0 International License, which permits any non-commercial use, sharing, adaptation, distribution and reproduction in any medium or format, as long as you give appropriate credit to the original author(s) and the source, provide a link to the Creative Commons licence, and indicate if changes were made. The images or other third party material in this article are included in the article's Creative Commons licence, unless indicated otherwise in a credit line to the material. If material is not included in the article's Creative Commons licence and your intended use is not permitted by statutory regulation or exceeds the permitted use, you will need to obtain permission directly from the copyright holder. To view a copy of this licence, visit http://creativecommons.org/licenses/by-nc/4.0/.

\section{References}

1. Dellon ES, Liacouras CA, Molina-Infante J, Furuta GT, Spergel JM, Zevit N, et al. Updated international consensus diagnostic criteria for eosinophilic esophagitis: proceedings of the AGREE Conference. Gastroenterology. 2018;155:1022-33.
2. Nonevski IT, Downs-Kelly E, Falk GW. Eosinophilic esophagitis: an increasingly recognized cause of dysphagia, food impaction, and refractory heartburn. Cleve Clin J Med. 2008;75(623-6):9-33.

3. van Rhijn BD, Smout AJ, Bredenoord AJ. Disease duration determines health-related quality of life in adult eosinophilic esophagitis patients. Neurogastroenterol Motil. 2014;26:772-8.

4. Safroneeva E, Coslovsky M, Kuehni CE, Zwahlen M, Haas NA, Panczak R, et al. Eosinophilic oesophagitis: relationship of quality of life with clinical, endoscopic and histological activity. Aliment Pharmacol Ther. 2015;42:1000-10.

5. Mukkada V, Falk GW, Eichinger CS, King D, Todorova L, Shaheen NJ. Health-related quality of life and costs associated with eosinophilic esophagitis: a systematic review. Clin Gastroenterol Hepatol. 2018;16(495-503):e8.

6. Dellon ES. Epidemiology of eosinophilic esophagitis. Gastroenterol Clin N Am. 2014;43:201-18.

7. Liacouras CA, Furuta GT, Hirano I, Atkins D, Attwood SE, Bonis PA, et al. Eosinophilic esophagitis: updated consensus recommendations for children and adults. J Allergy Clin Immunol. 2011;128:3-20.

8. Lucendo AJ, Molina-Infante J, Arias A, von Arnim U, Bredenoord AJ, Bussmann C, et al. Guidelines on eosinophilic esophagitis: evidence-based statements and recommendations for diagnosis and management in children and adults. United Eur Gastroenterol J. 2017;5:335-58.

9. Greuter T, Alexander JA, Straumann A, Katzka DA. Diagnostic and therapeutic long-term management of eosinophilic esophagitis: current concepts and perspectives for steroid use. Clin Transl Gastroenterol. 2018;9:e212.

10. Reed CC, Fan C, Koutlas N, Stefanadis Z, Eluri S, Shaheen NJ, et al. Compounded oral viscous budesonide is effective and provides a durable response in eosinophilic esophagitis. HSOA J Gastroenterol Hepatol Res. 2018;7:2509-15.

11. Dellon ES, Katzka DA, Collins MH, Hamdani M, Gupta SK, Hirano I, et al. Budesonide oral suspension improves symptomatic, endoscopic, and histologic parameters compared with placebo in patients with eosinophilic esophagitis. Gastroenterology. 2017;152(776-86):e5.

12. Edsbacker S. Budesonide capsules: scientific basis. Drugs of Today. 2000;36:9-23.

13. O'Donnell S, O'Morain CA. Therapeutic benefits of budesonide in gastroenterology. Ther Adv Chronic Dis. 2010;1:177-86.

14. AstraZeneca. Entocort EC (budesonide) [prescribing information] 2020. https://www.accessdata.fda.gov/drugsatfda_docs/label /2020/021324s023lbl.pdf. Accessed 30 Sept 2020.

15. Drozdzik M, Groer C, Penski J, Lapczuk J, Ostrowski M, Lai Y, et al. Protein abundance of clinically relevant multidrug transporters along the entire length of the human intestine. Mol Pharm. 2014; $11: 3547-55$.

16. Vertzoni M, Augustijns P, Grimm M, Koziolek M, Lemmens $\mathrm{G}$, Parrott N, et al. Impact of regional differences along the gastrointestinal tract of healthy adults on oral drug absorption: An UNGAP review. Eur J Pharm Sci. 2019;134:153-75.

17. Chen N, Cui D, Wang Q, Wen Z, Finkelman RD, Welty D. In vitro drug-drug interactions of budesonide: inhibition and induction of transporters and cytochrome P450 enzymes. Xenobiotica. 2018;48:637-46.

18. Nunes T, Barreiro-de Acosta M, Marin-Jimenez I, Nos P, Sans M. Oral locally active steroids in inflammatory bowel disease. J Crohns Colitis. 2013;7:183-91.

19. McNeil Products Ltd. RHINOCORT (budesonide) [prescribing information] 2010. https://www.accessdata.fda.gov/drugsatfda _docs/label/2010/020746s026lbl.pdf. Accessed 30 Sept 2019.

20. ClinicalTrials.gov. An extension study to evaluate maintenance of efficacy and long-term treatment effect of oral budesonide suspension (OBS) in Adults and adolescents with eosinophilic 
esophagitis (EoE) (ORBIT2). 2016. https://clinicaltrials.gov/ct2/ show/NCT02736409. Accessed 30 Sept 2019

21. ClinicalTrials.gov. A study in adolescents and adults with eosinophilic esophagitis (EoE) measuring histologic response and determine if reduction in dysphagia is achieved. 2015. https://clinicaltr ials.gov/ct2/show/NCT02605837. Accessed 30 Sept 2020

22. András Szeitza A, Manjib KJ, Riggsa W, Thamboob A, Javerb AR. Validated assay for the simultaneous determination of cortisol and budesonide in human plasma using ultra high performance liquid chromatography-tandem mass spectrometry. J Pharm Biomed Anal. 2014;90:198-206.

23. Edsbacker S, Bengtsson B, Larsson P, Lundin P, Nilsson A, Ulmius J, et al. A pharmacoscintigraphic evaluation of oral budesonide given as controlled-release (Entocort) capsules. Aliment Pharmacol Ther. 2003; 17:525-36.

24. Butler H. The veins of the oesophagus. Thorax. 1951;6:276-96.
25. Lechevrel M, Casson AG, Wolf CR, Hardie LJ, Flinterman MB, Montesano R, et al. Characterization of cytochrome P450 expression in human oesophageal mucosa. Carcinogenesis. 1999;20:243-8.

26. Lundin PD, Edsbacker S, Bergstrand M, Ejderhamn J, Linander $\mathrm{H}$, Hogberg L, et al. Pharmacokinetics of budesonide controlled ileal release capsules in children and adults with active Crohn's disease. Aliment Pharmacol Ther. 2003;17:85-92.

27. US FDA. Guidance for Industry, Investigators, and Reviewers: Exploratory IND Studies. 2006. https://www.fda.gov/downloads/ drugs/guidancecomplianceregulatoryinformation/guidances/ ucm078933.pdf. Accessed 30 Sept 2019

28. ClinicalTrials.gov. A Study in Adolescents and Adults With Eosinophilic Esophagitis (EoE) Measuring Histologic Response and Determine if Reduction in Dysphagia is Achieved. https://clini caltrials.gov/ct2/show/NCT02605837. Accessed 30 Sept 2020. 